\title{
nature
}

\section{Los Alamos deserves better}

The US Congress has turned the Los Alamos National Laboratory into a political pawn. The damage done will take a long time to rectify. Despite their mistakes, the national defence laboratories need far greater support from their country's leaders.

$\mathrm{S}$ o the flogging continues until morale improves. That is how a US government scientist characterized the position in which employees of the Los Alamos National Laboratory find themselves. It is a description that is all too apt. Whipping will probably continue for as long as it suits the political agendas of those, in Congress above all, doing the whipping, and at least until the presidential election in November. But the lab's lacerations will cut deep and take far longer to heal. What talented scientist will want to come and work at the laboratory with this lengthy public excoriation echoing in their memory?

Of course Los Alamos deserves criticism. Temporarily missing disks containing sensitive information about nuclear weapons should not have remained unaccounted for as long as they did. But it's worth putting that episode into perspective. The disks, containing information on US and other nuclear weapons, did not have the highest security classification. The people who used them were volunteers for an important job: tackling emergencies involving unexploded nuclear devices. The most plausible scenario for what happened is that one or more such volunteers acted irresponsibly, did not record taking the disks, then found themselves in the middle of a hunt. At some point, they decided to return them by dropping them behind a photocopier. The fact that much of this took place during a major threat to the lab's existence from forest fires, when the staff responded as best they could as homes were destroyed, is surely a mitigating fact to be considered.

The political agendas now in play need to be remembered. The energy secretary Bill Richardson, a partisan figure who, until this episode, was considered a possible running mate for Al Gore, is the real target of the latest bout of hysteria over lab security. Los Alamos and the Lawrence Livermore National Laboratory are caught up in the attacks on him.

But the politics are occurring against a background of longer-term decline in morale at those labs. Since the case of the alleged Chinese spy
Wen Ho Lee arose in 1998, they have faced a growing catalogue of obstacles to getting on with their main work - research needed to sustain the nuclear stockpile in the absence of nuclear testing. Security issues and congressional constraints have led to travel restrictions, scientifically unproven and insulting polygraph tests, obstacles to the hiring of foreign nationals, and cuts in spending at the discretion of lab directors. The growth in bureaucracy and uncertainty in programme status have undermined the labs' attractiveness as places with which to collaborate. Above all, they bear a growing burden of micro-management from congressional committees and their staff.

Of course, the laboratories themselves have not adapted quickly enough to the post-cold-war environment. Huge cost overruns at Lawrence Livermore's national ignition facility for fusion research are an example of how the labs' lack of accountability has undermined their credibility. But the damage now being done to their reputation is disproportionate to their sins. These laboratories are not only essential for the nuclear and, increasingly, biological security of the United States. They can also bring interdisciplinary skills and scales of effort to bear on other important research topics in a way that few other laboratories can.

Earlier this week, Richardson announced that the University of California will be asked to renegotiate its contract for running the labs and thereby lose its responsibility for lab security. But the difficulty of balancing science and security at the labs has been apparent since the start of the Manhattan Project during the Second World War, and many participants in the current debate seem ignorant of the inherent difficulties of running a nuclear weapons research programme in a country as committed to freedom of information as is the United States. The incoming administration will have no option but to shake off the political invective and move rapidly to rebuild public confidence in what remain jewels in the US research crown, whose very future as top-quality research laboratories is now in danger.

\section{Declaration for AIDS sufferers}

A declaration about HIV as the cause of AIDS should be accepted and thus bring an end to a tragic debate in South Africa.

$\mathrm{T}$ he "Durban Declaration", which is published as a Commentary on page 15 , has been signed by scientists, doctors and senior representatives of all the world's leading medical and scientific research organizations and government authorities engaged in HIV/AIDS research or policy - UNAIDS, medical research institutes, leading universities and independent research foundations. But, crucially, the declaration is also supported by health ministers, AIDS experts and public-health officials from countries in Africa, Asia and elsewhere in the developing world (see page 3 ).

The declaration is a massive international response to recent debates in South Africa, and is made on behalf of people infected with HIV. Frustrated at a needless and tragic delay in treating sufferers, the authors see the declaration as a decisive rejection of arguments put forward by many of those on a panel set up by South African President Thabo Mbeki to "re-evaluate" the cause of AIDS. As described in the declaration, the evidence for HIV as the cause of AIDS is overwhelming. Drugs such as AZT can be used relatively cheaply and effectively to reduce mother-to-child transmission of this virus. (Readers interested in further details about HIV as the cause of AIDS can see http://www.niaid.nih.gov/factsheets/evidhiv.htm. Those wishing to assess the opponents' case might visit http://www.duesberg.com.)

Unlike some websites disputing the evidence that HIV is the cause of AIDS, to which anyone can apparently add their support regardless of their expertise, the Durban Declaration is signed only by scientists and representatives of organizations involved in research and treatment of AIDS. That is not the reason Nature endorses their position, however - indeed, Nature takes pleasure in publishing papers that convincingly overturn widely accepted hypotheses. It is, rather, on the compelling basis of the science that we urge that the declaration's message be acted upon by President Mbeki and his government. 